\title{
Multicultural Arts Education in the Post-Secondary Context?: Creating Installation and Performance Art in Surrey, Canada
}

\author{
Sasha Colby \\ Simon Fraser University \\ Canada
}

In 2007, Simon Fraser University's satellite campus in Surrey, British Columbia, received an Official Languages Dissemination Grant from the Social Sciences and Humanities Research Council of Canada to examine the role of official bilingualism in the multilingual context through installation and performance art. This essay considers the processes of creating student-based art about language identity in the case-specific example of Surrey. Positing the significantly multilingual community of Surrey as a "microcosm of the emerging national reality," the author discusses the challenges of representation, the "concealing art" that unchallenged official bilingualism represents, as well as the social benefits of making centralized public arts space a legitimate venue for multicultural arts education and student-based expressions about language and identity.

History and Context

Preparing Through Literature

Art Making

Conclusion

References

\section{History and Context}

In the fall semester of 2007, students in the Explorations in Arts and Social Sciences program at Simon Fraser University Surrey embarked on a onesemester project: the creation of installation and performance art that reflected on themes of linguistic identity in a context that, like much of Canada, is at once significantly multilingual and officially bilingual. Thirteen second- and third-year undergraduate students, from diverse linguistic and cultural backgrounds and ranging in age from 19 to 21 , carried out the project, assisted by a graduate research assistant from the Department of Contemporary Arts at Simon Fraser and a supervising professor, the author of this article. The project was funded by an Official Languages Dissemination Grant administered by the Social Sciences and Humanities Research Council of Canada. The form and direction of the performances and installation art were student-led, reflected youth experiences and expressions, and consequently provided a candid look at the young Canadianism of the digital age. The project as a whole created a powerful 
confrontation of youth, official bilingualism, and lived multilingualism, as well as the challenges of artistic representation. As a result it yielded unusual insight into the perspectives of youth culture on national and linguistic identities, views that are often under-represented and diverge from visions that have been offered by professional artists and academics. Set against the larger Canadian context, the project poses interesting cultural questions about pluralism, representation, and the role of multicultural arts education in creating spaces for social dialogue.

The Voicing the Mosaic project took place within the context of a course called "Explorations 320: Culture, Memory, Writing and Performance." The Explorations Program is an interdisciplinary cohort program at Simon Fraser University Surrey, and Explorations 320 is designed to challenge students to take their theoretical knowledge into the community and have it confronted and enriched by lived experience. The project centered around exploring ideas of diversity, linguistic identity, and arts-based social representation. As a result, it subscribed to what is broadly referred to as multicultural arts education, which several art educators have assessed for both its pedagogical and civic possibilities (Adejumo 2002; Banks \& McGee Banks, 2010; Grant \& Sleeter, 2007; Stuhr, 1994,1999). At the root of multicultural arts education is the belief that art can be a transformative, empowering mode of learning and expression (Bailey \& Desai, 2005; Eisner, 2004; Smith, 2010). In particular, it has been argued that community-based arts projects that bring students into a closer experiential relationship with their daily realities can have a powerful effect on both perception and awareness of their communities (Graham, 2009). Stuhr (1994), who has argued convincingly for the role multicultural arts education can play in social reconstruction, has nonetheless stressed the ways in which not every multicultural arts education practice challenges "dominant power and knowledge structures that tend to create sociocultural inequities" (p. 171). It is only when educational structures themselves accommodate ideas of equity and diversity that they can in turn produce environments that foster democratic and equitable thought and behavior (p. 175). As a result, Stuhr argues, "Multiculturalism in art education can claim a relationship to radical social reconstruction only in so far as the approach taken and practiced through curriculum design, teaching methods, content, goals and objectives is congruent with this type of belief system" (p. 178). For Stuhr, multicultural arts education that strives to bring about a more inclusive society must therefore be inclusive in its content and structures, with particular emphasis on student-led creative expression and adequate space for diversity in representation.

A good example of a project that embodies the type of multicultural arts education that Stuhr advocates is Mark Graham's 2009 International Stories Project. During the course of Graham's project, students were sent "into the community to document the experiences and stories of the people who live there" (p. 155). Graham termed this activity "cultural journalism," the documentation of lived histories and testimonies from community members, an approach which seeks to "engender empathy, compassion, and intercultural dialogue, and encourage students and teachers in critical thinking about cultural assumptions and diversity" (p. 155) by connecting with community members, documenting 
their stories, and representing them through art photography and other types of visual art. Cohesive with Stuhr's view, the students were encouraged to make their own choices about subject matter and representation within the parameters of the project. Similarly, the Voicing the Mosaic students were also sent into the community with a sense of informed choice. With instruction on interviewing and ethics as well as university-vetted permission form, students were encouraged to ask community members to share their stories about language and belonging on video camera. In addition to providing an opportunity to experience multiple perspectives on community members' experiences, this footage provided students with a basis for self-reflection and was the raw material out of which the students would subsequently build their installation project and create their performance pieces.

In honing a greater awareness of their surroundings, the Voicing the Mosaic students were also asked to contextualize their findings within an empirical sense of the city's history and demographics. The ground out of which Voicing the Mosaic was built was the city of Surrey, a community in British Columbia's Lower Mainland where $47 \%$ of census respondents over the age of 15 are first generation Canadians (Canadian Census, 2006). In Surrey, 45.8\% of the population is a visible minority. At home, one third primarily speak a language that is not of the official variety (English and French). In many ways, Surrey is a predictor, a microcosm of the emerging national reality. Similarly, the student body of the Simon Fraser University campus reflects the multilingual makeup of its environment. When Simon Fraser took over the campus from the Technical University of British Columbia in 2002, it was a make-shift space rented from the Central City Mall. Students passed the discount department store, Zellers, and the food court on their way to class. By 2007, a mezzanine and three stories of galleria space had been built to accommodate the University. In the center, still only steps away from the public mall, is the Dale B. Regher mezzanine, an airy intermediary space contained by chrome, wooden beams, and green glass. It is this space, in the center of Surrey, within the University but attached to a busy commercial shopping area, that housed the public art project.

Surrey, originally a suburb of Vancouver but now projected to overtake it in population by 2020 , has the ironic history of a traditionally low income area pushed into the spotlight by multiculturalism based more on economics than trendy politics. "Surrey" received its name from a homesick Englishman who saw something of his hometown in the green landscape across the Fraser River, while the center of Surrey, "Whalley," was later named after the owner of a local gas-bar and was built on the burial ground of the Kwantlen Nation. While sections of Surrey have become affluent, Whalley is marked by a noticeable drug trade and other urban ills. The city has made a significant push toward gentrification of the downtown areas with a mixed success that has seen the arrival of condominium developments but a homeless problem that has been dispersed rather than diminished. The ' $80 \mathrm{~s}$ and '90s witnessed the arrival of a significant wave of immigrants, particularly from South East Asia, with the most 
significant jump in immigration numbers occurring between 1991 and 2000 (Canadian Census, 2006). The city's motto "the future lives here" can be read in several ways, certainly as a desire to identify the city with its growing potential rather than with its past reputation, but also as a gesture toward a significant portion of the population that left its countries of origin in search of a new beginning. In preparing for the arts project, students researched and provided oral and written reports on Surrey's history as well as the region's language demographics.

\section{Preparing Through Literature}

As a complement to creating multicultural art, several education and multicultural education theorists have commented on the value of studying literature in encouraging students to think more widely and more empathetically about their surroundings (De León, 2002; Rabin, 2010; Roche, 2004). In thinking about Surrey, students were assigned a variety of theoretical and creative works on language and identity, including John Ralston-Saul's assessment (1997) of the Canadian milieu: "Since the eighteenth century Canada has functioned as a confusion of minorities major and minor. This is what the country is" (p. 111). More than just something that must be contended with, Saul underlines the advantages of this heterogeneity: "What makes Canada interesting is that it was built upon the assumption that a jarring note was a positive thing.... It is the doubt, the questioning, the uncertainty which is there to keep us focused on the idea of the society rather than slipping into the old nationalist certitudes" ( $p$. 129). This idea of the mosaic as the undercutting of exclusionary national fervor has held a certain amount of sway as an appealing way of thinking about tolerance and accommodation. While this idea of Canadian society has much ideological appeal, however, it has not solved the practical realities of alienation and exclusion or the related quandary of representation. At the end of the day, the central tension in creating art about pluralism is the pull between the multitudinous variety of experiences and identities, on the one hand, and the need for some kind of realizable artistic vision, on the other hand. With the absence of a common history, an understood body of images, or the mastery of a common language, art designed for public presentation, particularly that which broaches questions of language and identity, must in effect re-invent itself in order to be both inclusive and effective.

In addition to Ralston-Saul, students were also exposed to ideas such as those of Homi Bhabha, who has stressed both the creative and the "hybrid" notion of identity in his seminal text, The Location of Culture (1959). Central to hybridity is the understanding that those possessing backgrounds and languages other than the dominant ones exist in a "third space" between their home culture and the culture in which they currently dwell. Bhabha presents the construction of the immigrant's self-identity as a delicate balance between retaining the self 
that was imagined at home and the acceptance of new states of being brought about by the processes of migration. It is "politically crucial," Bhabha writes, to think beyond "narratives of originary and initial subjectivities" and to move into "in-between" spaces that "provide the terrain for elaborating strategies of selfhood - single or communal - that initiate new signs of identity, and innovative sites of collaboration, and contestation, in the acts of defining the idea of the society itself" (p.7). An important element here is the way in which Bhabha perceives the re-imagining of selfhood to be intricately linked to the "idea of the society," a meditative theory on how the re-imaging of ourselves may be an instrument of collective change. But also key to a consideration of language identity and the arts is the way that Bhabha highlights the creative aspects of identity-formation: "[l]t is the space of intervention emerging in the cultural interstices that introduces creative invention into existence. And one last time, there is a return to the performance of identity as iteration, the re-creation of the self in the world of travel, the resettlement of the borderline community of migration" (p. 9).

With Saul's idea of the "jarring note" and Bhaba's concepts of hybridity in mind, the students then read a variety of creative works that explored the tensions and creative possibilities of co-existent language subjectivities. For example, the students read works by Canadian Caribbean writers such as Austin Clarke $(2003,2007)$, who frequently integrates pidgin or patois into the fabric of his texts, as well as poets such as Lola Tostevin $(1991,2004,2007)$ who plays with the gaps and silences in understanding between Canada's two official linguistic groups, anglophones and francophones. Students were particularly responsive to close-readings of Tostevin's poem "Gyno-text," where we explored her complex understanding of the "in-between" of languages:

$$
\begin{gathered}
\text { a } \\
\text { different } \\
\text { tongue } \\
\text { to } \\
\text { pen } \\
\text { a } \\
\text { trait } \\
\text { le } \\
\text { trait } \\
\text { d'union }
\end{gathered}
$$

Here, the English and French simultaneously work together to further the text while at the same time the punning undermines the text's coherence: to 
"pen a trait" suggests an ability to master a characteristic in writing, while "le trait d'union" is literally a hyphen, the joining space between two things. The English "trait" which seemed easy to pin (or pen) down becomes much more slippery when its doppelganger, the "trait," is introduced in all of its intermediary, linking, and contingent suggestiveness. The hyphen itself becomes symbolic of the "inbetween" space that is being explored, the gaps that exist within linguistic and national "union." While the tone of the text is playful, Tostevin is making an important point about the ways in which languages can at once work together and undermine each other's monopoly on meaning - an interesting linguistic equivalent to Saul's evocation of doubt, questioning, and uncertainty as foundational to the ongoing task of civil society making. This reading helped to ground students in more complex ideas about the possible combinations of languages and identities before they themselves began to "make art" out of the experiences and video footage they had gathered.

\section{Art Making}

After a month of literary and theoretical readings and demographic research, which was complemented by the video-recorded interviews, students were ready to begin making sense of what they had gathered and to transform it into creative form. A notable aspect of the interviews was the diversity of the respondents. Interviewing across generations, cultures, and languages, students spoke to a variety of Surrey residents on campus, out of doors, and in their homes. In addition, the third-year students collected anonymous journal responses from first-year Explorations students, asking them to comment on their experiences with language and identity in Canada. Interestingly, the responses of older generations and younger generations of new Canadians were remarkably similar in both tone and content. Many felt happy to be a part of a relatively free, democratic society, but most had encountered some form of discrimination or prejudice due to language or accent.

The following stories are representative examples. One student described the humiliation of arriving in Canada, being placed in the seventh grade, despite the fact he was several years ahead in his own country, and being taunted by his classmates for an English vocabulary that consisted of two words: "apple" and "orange." Another student wrote of her embarrassment when her mother would "rant" at her in French in front of her English-speaking friends. These stories were developed into monologues and scenes, as were experiences with language difficulty and official recognition central to the student artists' own lives. In describing the transformation of family history into a scene for the Voicing the Mosaic performance piece, one student noted:

We came up with the janitors' scene as a sort of spur of the moment idea.... We were thinking about our parents and how when they came to 
Canada their credentials weren't recognized. And so you could have a genius working as a janitor in Canada which is not exactly right but ... we're actually hoping to really stress that fact. I know it's not really a good thing but sometimes if you speak to something it will change. (Explorations 320, 2007)

Desire for change also shaped scenes that students scripted from more public encounters. Surrounded by social contexts in which language interactions can result in enrichment as well as practical difficulties, one student described observing a Cantonese speaker overwhelmed and frustrated by the difficulties of communicating his destination to an English-speaking bus driver. Replicating the experience in the performance piece, the students enacted the passenger's agitation and distress in attempting to find out if the public bus was going to "Granville Street." In the clash of languages and accents, the Cantonese speaker becomes increasingly frustrated until the intervention of an interpreter, a fellow passenger. This scene, in particular, struck a chord with audiences. After one public performance, I received the following email from a member of the SFU Surrey staff:

Thank you to you and your students for this morning's performance; I love to see political and social issues explored through theatre and art. Please congratulate the students for an energetic and moving piece. During the scene on the bus, I was eerily reminded of poor Robert Dziekanski at YVR.

The story of Robert Dziekański, a Polish immigrant fatally tasered by the Royal Canadian Mounted Police at the Vancouver airport on October 14, 2007, for no apparent reason other than agitation and a language barrier that prevented him from expressing his needs in an official language, was very much in the air during the November staging. The public inquiry into Dziekański's death did not begin until May. Though anecdotal, the fact that several audience members commented on the Dziekański case in the question-and-answer session after the performance seemed to suggest that in this case the art project was able to play a significant role in the absorption and concentration of collective emotion about the role of languages in the just society.

In addition to the performance art, students also constructed a large piece of installation art which explored similar themes. In preparing for the conceptualization and building of the art work, students considered the history of public art and the need for new, more representative models. As many have pointed out, public art has more often been used as a tool to enforce singularity rather than to unveil the nature of the plural (Adamek \& Lorenz, 2008; Gérin \& Mclean, 2009). The artistic transformation of public space is not neutral or decorative. It is political and ideological, which has resulted in restrictions to access. As Annie Gérin (2006) writes: "Public art serves to claim territory for a (cultural, social, political, ideological) purpose, and it claims to anchor it by the characteristic durability of its materials" (p. 326). Turning to the example of the Quiet Revolution, Gérin notes that during this time public artworks "produced the illusion of straightforward ownership of Québecois spatiality of the Québecois, 
concealing the vicariousness of public spaces as well as cultural identities" ( $p$. 326). While Quebec in the 1960s is the example, here, it is rather universally true that it has been easier and more politically advantageous to create public art that conceals rather than one that can be called genuinely revelatory. The narrative of official bilingualism, while bi-lingual and bi-cultural, would also represent a concealing art in a community like Surrey.

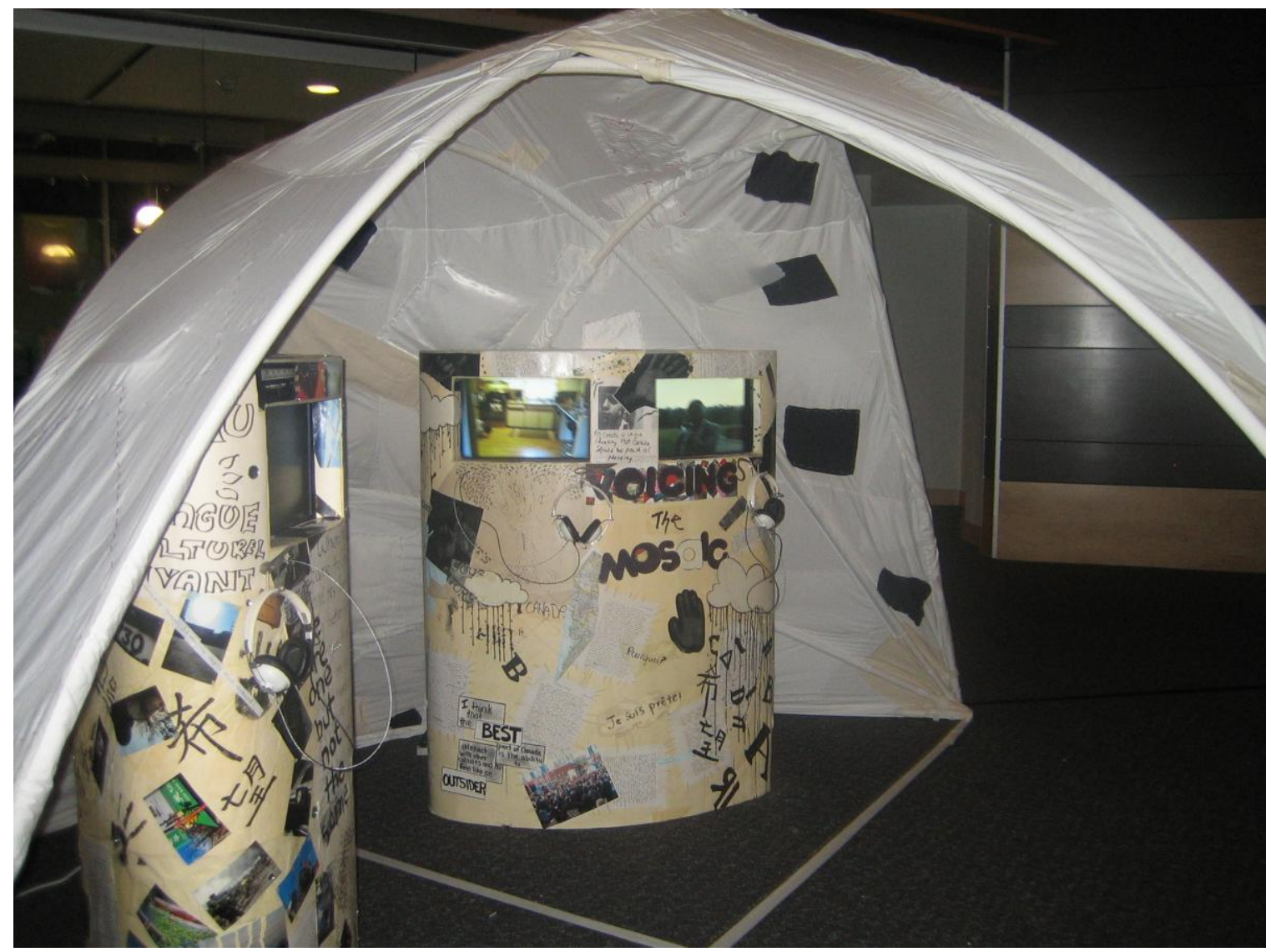

The Voicing the Mosaic students therefore realized that their public representation must depend on the acknowledgement and representation of languages and narratives both official and unofficial, of an official bilingualism which must be interlaced and at times displaced by voices that speak other tongues. The dialectic of inclusion, artistic and political, relies on a willingness to negotiate new shades of identity through an engagement with hybridity -and not just for the newly arrived. As a result, the students were keen to reveal both the positive and negative aspects of a society that brands itself as officially "multicultural" yet only recognizes two languages, and to use technology in ways that highlighted the gaps, silences, and unexpected insertions of their interview subjects. After considering many possible approaches, the students opted to use a combination of video and written materials. The Voicing the Mosaic installation was 12x18 feet and consisted of a half-shell dome made of cotton and synthetic materials housing four televisions running simultaneous interviews 
with Surrey residents about their experiences with language and identity in Canada. In addition, three-and-a-half foot platforms, four feet in diameter with three steps protruding toward the front, were swathed with messages to the audience, multi-lingual stories about the Canadian linguistic experience, largely drawn from the first-year students' journal writing. Mannequins pasted with various languages and written characters stood atop each platform, a gesture toward the embodied nature of linguistic identity. The videos, which played on continuous loop within the half-shells, showed the people of Surrey speaking for themselves; the messages were layered, multiple, and uncontained by a central object lesson. But it also illustrated a type of coherence specific to the sensemaking of millennial multicultural Canadian youth: the energy of multiplicity as it exists in its tangential, persistently shifting form, a "unity" that is paradoxically a dis-unity existing within the boundaries of the civic society. These students did not see the multiple and the multilingual as something that exists on the fringes of a dominant culture. They saw it as the center.

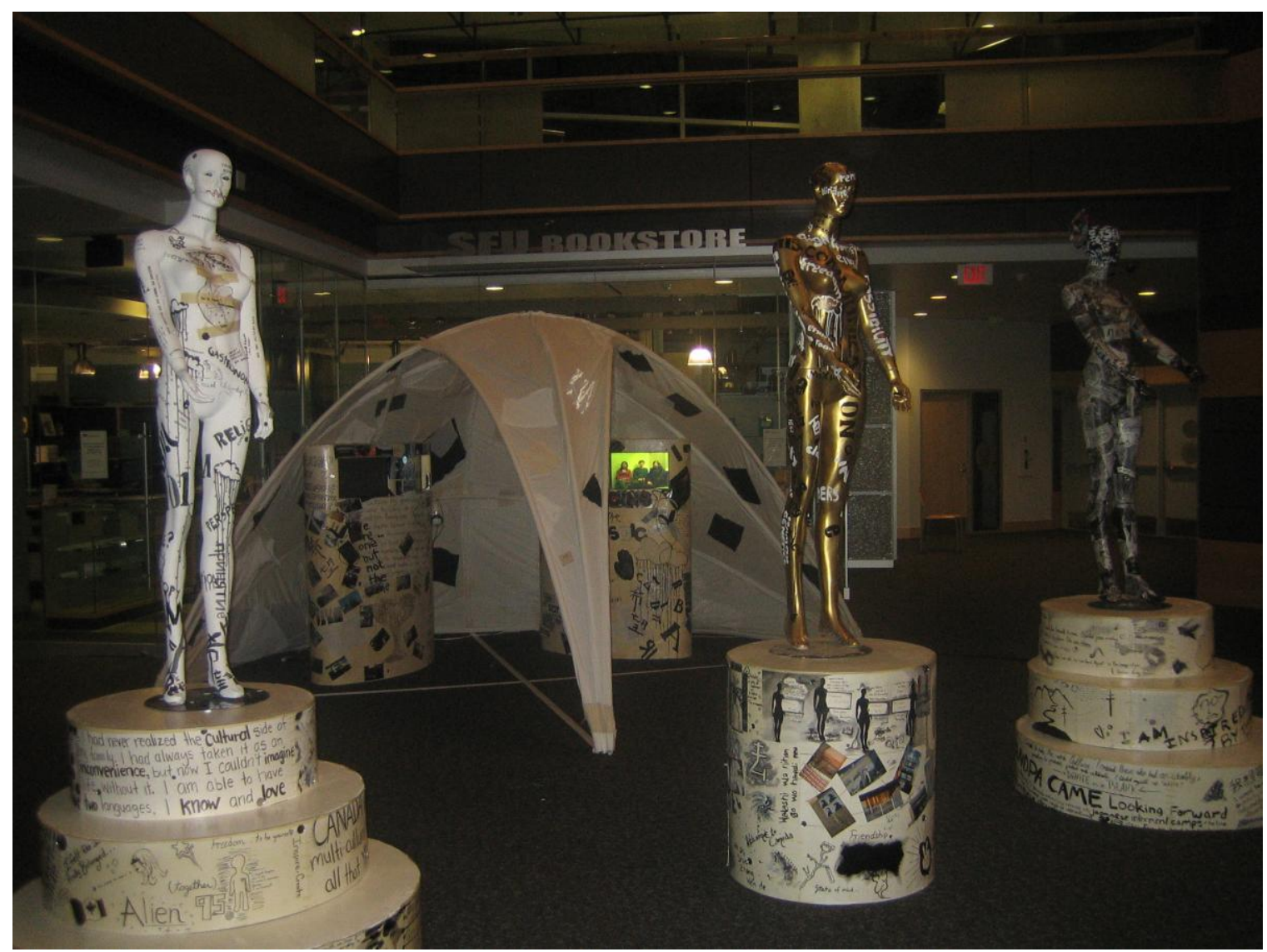

\section{Conclusion}

The Voicing the Mosaic Project was an experiment in bringing together cultural theory with community interviews and arts education practice. In 
grounding students in literature that expanded their sense of linguistic identity and inclusiveness while giving them a great deal of artistic freedom, the project existed within the parameters of Stuhr's (1994) view of a multicultural education practice that enables students to participate in the processes of social reconstruction. Certainly the students emerged with a strong feeling for their own role in promoting social dialogue. When, as Stuhr suggests, students are enabled to represent themselves freely in arts education contexts, their ability to transform blank space, civic space, and public space into locations for thoughtful collective consideration should not be underestimated. Bhabha's (1959) insistence on identity formation as an inherently creative process and the social ramifications of this invitation open the door to a realm where arts production contributes to the re-imagination of the social body. This is not a utopian exercise. It is as much about materializing and confronting our social ills as it is about dreaming something else. Creative access to centralized, physical environments is a spatial metaphor. It speaks very clearly. It says, "Welcome to the conversation." For the students at SFU Surrey, engaging in this dialogue permitted them to express an inclusive vision of the languages and experiences that contribute to Canadian identity. Furthermore, it allowed them to present their ideas, through installation and performance art, to the University and greater community in a way that fostered both theoretical discussion and the more intimate sharing of stories and experiences. As a result, Voicing the Mosaic provided a transformative experience for students that exceeded a conventional academic survey of multicultural themes. The project therefore suggests that multicultural arts education can be a powerful complement to a traditional postsecondary curriculum, one that both enriches standard practice and creates new pathways to learning and understanding.

\section{References}

Adamek, M., \& Lorenz, K. (2008). "Be a crossroads": Public art practice and the cultural hybrid. In C. Cartiere \& S. Willis (Eds.), The practice of public art (pp. 56-65). New York: Routledge.

Adejumo, C. (2002). Considering multicultural art education. Art Education, 55(2), 33-39.

Bailey, C., \& Desai, D. (2005). Visual art education: Engaged visions of history and community. Multicultural Perspectives, 7(1), 39-43.

Banks, J. A., \& McGee Banks, C. A. (Eds.). (2010). Multicultural education: Issues and perspectives (7th ed.). Hoboken, NJ: John Wiley \& Sons.

Bhabha, H. (1959). The location of culture. New York: Routledge.

Clarke, A. (2003). Choosing his coffin: The best stories of Austin Clarke. Toronto, Canada: T. Allen Publishers. 
Clarke, A. (2007). There are no elders. Toronto, Canada, Canada: Exile Editions.

Eisner, E. (2004). The arts and the creation of mind. New Haven, CN: Yale University Press.

Explorations 320. (2007). Voicing the mosaic: The making of. (Documentary DVD). Surrey, Canada: Simon Fraser University.

Gérin, A., \& Mclean, J. S. (2009). Public art in Canada: Critical perspectives. Toronto, Canada: University of Toronto Press.

Gérin, A. (2006). Maîtres chez nous: Public art and linguistic Identity in Quebec. In G. Sherbet, A. Gérin, \& S. Petty (Eds.), Canadian cultural poesis (pp. 323-341). Waterloo, Canada: Wilfrid Laurier Unversity Press.

Graham, M. (2009). The power of art in multicultural education. Multicultural Perspectives, 11(3), 155-161.

De León, L. (2002). Multicultural literature: Reading to develop self-worth. Multicultural Education, 10(2), 49-51.

Grant, C., \& Sleeter, C. (2007). Doing multicultural education for achievement and equity. London: Routledge.

Rabin, C. (2010). Fostering dispositions through the literary arts. Action in teacher education, 31(4), 14-27.

Roche, M. (2004). Why literature matters in the $21^{\text {st }}$ century. New Haven, CT: Yale University Press.

Saul, J. R. (1997). Reflections of a siamese twin: Canada at the end of the twentieth century. Toronto, Canada: Viking.

Smith, J. (2010). Biculturalism and multiculturalism: Competing tensions in visual arts education in Aotearoa - New Zealand. International Journal of Multicultural Education, 12(2), 1-18.

Statistics Canada (2006). Community profiles: Surrey, British Columbia. Retrieved from http://www12statcan.ca

Stuhr, P. (1999). Review of: Celebrating pluralism: Art, education, and cultural diversity. Studies in Art Education, 40(2), 180-191.

Stuhr, P. (1994). Multicultural art education and social reconstruction. Studies in Art Education, 35(3), 171-178.

Tostevin, L. (2007). Punctum. Victoria, Canada: Nomados Literary Publishers.

Tostevin, L. (2004). Site-specific poems. Toronto, Canada: The Mercury Press.

Tostevin, L. (1991). Gyno-text. In S.Thesen (Ed.), The new long poem Anthology (pp.14-18). Toronto, Canada: Coach House Press. 